\title{
Synthesis, spectroscopic, electrochemical and luminescence studies of ruthenium (II) polypyridyls containing multifunctionalized 1,2,4-triazole as co-ligand
}

\author{
LALLAN MISHRA* and AJAY K YADAW \\ Department of Chemistry, Faculty of Science, Banaras Hindu University, \\ Varanasi 221 005, India \\ e-mail: lmishra@banaras.ernet.in
}

MS received 23 February 2000; revised 26 June 2000

\begin{abstract}
Ruthenium (II) 2,2'-bipyridyl and 1,10-phenanthroline complexes with 4amino-3-hydrazino-5-mercapto-1,2,4-triazole $\left(\mathrm{LH}_{2}\right)$ as co-ligand were synthesised and characterized by elemental analysis, IR, UV/Vis, ${ }^{1} \mathrm{H}$ NMR spectra and FAB-mass data. The electrochemical and luminescent properties of the complexes were also studied.
\end{abstract}

Keywords. Ruthenium (II) polypyridyls; 4-amino-3-hydrazino-5-mercapto-1,2,4triazole; $\mathrm{N}_{2}$-complex.

\section{Introduction}

Substituted 1,2,4-triazoles have attracted attention owing to their bactericidal ${ }^{1}$, fungicidal $^{2}$ and pharmacological activities ${ }^{3,4}$ in addition to their uses as antiulcer ${ }^{5}$ and blood-pressure-lowering agents ${ }^{6}$. Furthermore, it is known ${ }^{7,8}$ that $\mathrm{RuCl}_{3} \cdot 3 \mathrm{H}_{2} \mathrm{O}$ reacts with hydrazine to form its $\mathrm{N}_{2}$ complex which is of great interest in the chemistry of $\mathrm{N}_{2}$ fixation. Triazoles are also the subject of extensive studies in view of their synthetic properties and other theoretical aspects ${ }^{9}$. Ruthenium (II) polypyridyl complexes have opened a new door for enthusiastic researchers since they act as probes for DNA and hence are potential therapeutic agents ${ }^{10}$. Thus, in view of these facts and in continuation of our earlier studies ${ }^{11}$, we selected the commercially available 4-amino-3-hydrazino-5mercapto-1,2,4-triazole as co-ligand since it possesses properties that can be exploited for use as complexing agent with ruthenium (II) polypyridyls. Our surmise that the hydrazino part of this ligand could be converted into $\mathrm{N}_{2}$ also enthused us to take up the present investigation.

\section{Experimental}

\subsection{Materials and physical measurements}

All solvents were distilled prior to use. 4-Amino-3-hydrazino-5-mercapto-1,2,4-triazole, 2,2'-bipyridine, 1,10-phenanthroline, lithium-chloride and $\mathrm{RuCl}_{3} \cdot 3 \mathrm{H}_{2} \mathrm{O}$ were purchased

*For correspondence 
from Aldrich and used as supplied, whereas cis- $\mathrm{Ru}(\mathrm{bpy})_{2} \mathrm{Cl}_{2} \cdot 2 \mathrm{H}_{2} \mathrm{O}$ (bpy $=2,2^{\prime}$ bipyridine) and $\mathrm{Ru}(\mathrm{Phen})_{2} \mathrm{Cl}_{2}$ (Phen $=1,10$-phenanthroline) were prepared following the procedure reported ${ }^{12}$ by Meyer et al. The complexes of ruthenium (II) were prepared under $\mathrm{N}_{2}$ atmosphere and the progress of reaction was monitored by TLC. The complexes were purified by column chromatography using neutral alumina as support.

Microanalyses and FAB-mass data were carried out at the Central Drug Research Institute, Lucknow using Carlo Erba Elemental Analyser 1108 and JEOL SX-102 respectively. Absorption, luminescence and electrochemical studies were carried out at the University of Tokyo, Japan. IR spectra of the triazole and its ruthenium (II) polypyridyl complexes were recorded in the region $4000-400 \mathrm{~cm}^{-1}$, using Perkin-Elmer 783 spectrophotometer whereas ${ }^{1} \mathrm{H}$ NMR spectra (DMSO- $d_{6}$ ) were recorded on JEOL $F x$ 90Q spectrometer.

\subsection{Ligand and complexes}

Commercially available 4-amino-3-hydrazino-5-mercapto-1,2,4-triazole $\left(\mathrm{LH}_{2}\right)$ was used as the ligand for all the complexes. Ruthenium (II) polypyridyl complexes were synthesized following the general procedure reported ${ }^{11}$ earlier.

2.2a $\left[R u_{2} L(b p y)_{4}\right]\left(P F_{6}\right)_{2} 2 D M S O$ (1): An ethanolic solution of $\mathrm{Ru}(\mathrm{bpy})_{2} \mathrm{Cl}_{2} \cdot 2 \mathrm{H}_{2} \mathrm{O}$ $(0.520 \mathrm{~g}, 1 \mathrm{mmol})$ was mixed with a clear solution of the ligand $\mathrm{LH}_{2}(0.073 \mathrm{~g}, 0.5 \mathrm{mmol})$ in DMSO $(5 \mathrm{ml})$. The resulting solution was refluxed for $25 \mathrm{~h}$, and then filtered after keeping overnight at room temperature. The concentrated filtrate was precipitated by the addition of saturated aqueous solution of $\mathrm{NH}_{4} \mathrm{PF}_{6}$, the crystalline solid thus obtained collected by centrifugation, then washed with water and ethanol, and finally with diethyl ether.

2.2b $\left[R u\left(N_{2}\right)(P h e n)_{2} D M S O\right]\left(P F_{6}\right)_{2} D M S O(2):$ An ethanolic solution of $\mathrm{Ru}(\mathrm{Phen})_{2} \mathrm{Cl}_{2}$ $(0.532 \mathrm{~g}, 1 \mathrm{mmol})$ was mixed with a clear solution of the ligand $\mathrm{LH}_{2}(0.073 \mathrm{~g}, 0.5 \mathrm{mmol})$ in DMSO $(5 \mathrm{ml})$. After refluxing the solution for $25 \mathrm{~h}$, the complex was isolated adopting a procedure similar to that discussed in $\$ 2.2$ a.

2.2c Purification: Both ruthenium (II) complexes thus obtained were purified using column chromatography on neutral alumina support, using $\mathrm{MeCN}$ as eluent. The solid mass from the respective eluates, after evaporation of solvent, was dissolved in acetone then reprecipitated by addition of a saturated aqueous solution of $\mathrm{NH}_{4} \mathrm{PF}_{6}$. The crystalline solids obtained for both complexes were washed successively with water, ethanol and diethyl ether, and finally dried under vacuum.

The analytical data along with the physical properties of the complexes are reported in table 1.

\section{Results and discussion}

Based on elemental $(\mathrm{C}, \mathrm{H}, \mathrm{N})$ analysis and FAB-mass data, molecular compositions assigned to the ruthenium (II) complexes are shown in table 1. The complexes are thermally stable and soluble in MeCOMe, MeCN, DMF and DMSO. 


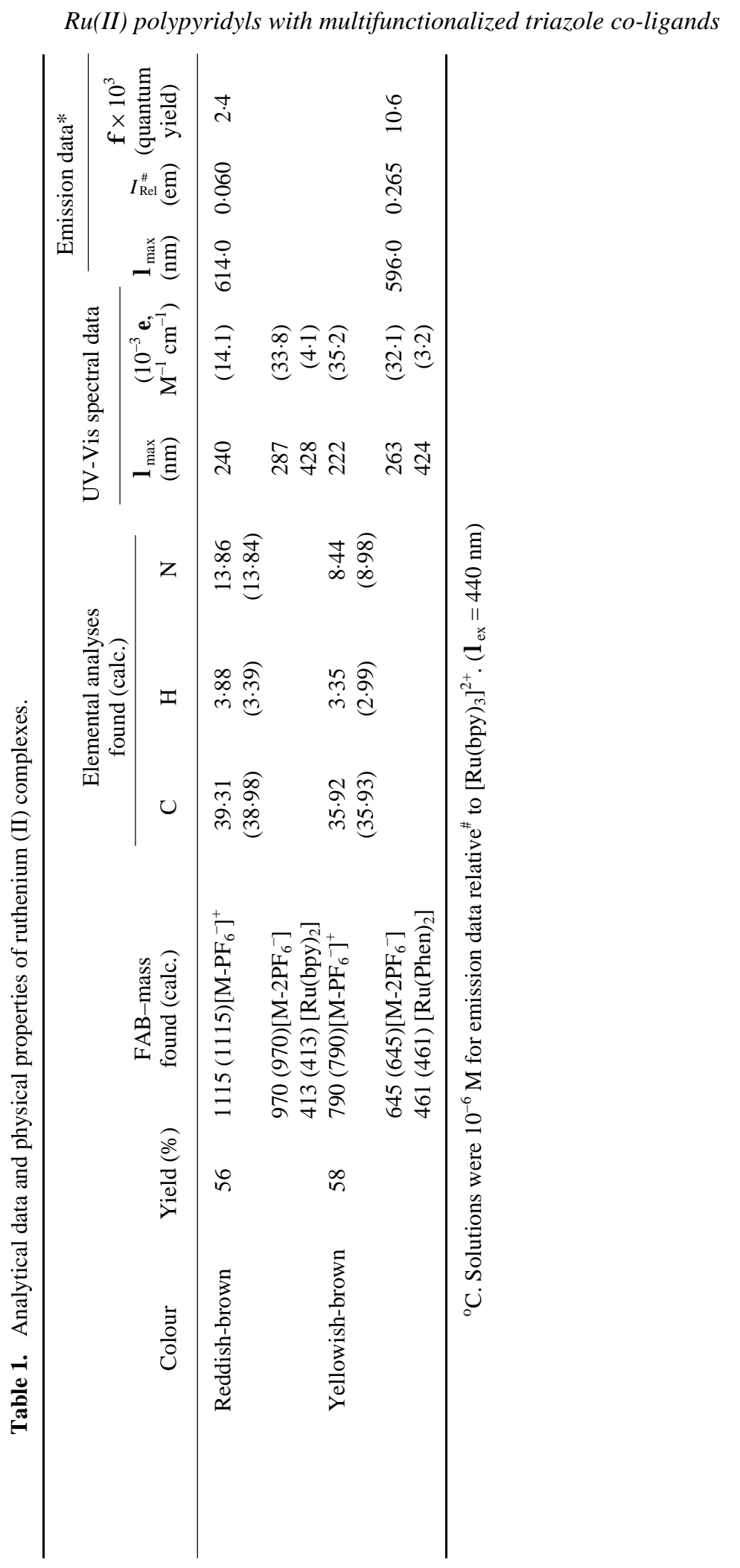




\subsection{IR spectra}

IR spectral peaks observed at 1280 and $1580 \mathrm{~cm}^{-1}$ for the free ligand $\left(\mathrm{LH}_{2}\right)$ were assigned $^{13,14}$ as $v(C=S)$ and $v(C=N)$, which were shifted to $\sim 1250$ and $1480 \mathrm{~cm}^{-1}$ respectively in the spectra of the complexes. This low energy shift supports their coordination with the metal ion. However, the IR spectrum of complex $\mathbf{2}$ shows an additional intense peak at $1992 \mathrm{~cm}^{-1}$ which was not observed in either the earlier complex or in the free ligand. This peak was assigned as $v\left(\mathrm{~N}_{2}\right)$ in view of the earlier reports ${ }^{9,15,16}$. Furthermore, the IR spectrum of the complex isolated after reaction of free $\mathrm{LH}_{2}$ with $\mathrm{RuCl}_{3}-3 \mathrm{H}_{2} \mathrm{O}$ also shows a strong peak at $1980 \mathrm{~cm}^{-1}$ due to $v\left(\mathrm{~N}_{2}\right)$. Thus, in view of this observation, we consider that the ligand during complexation in DMSO is oxidized generating $\mathrm{N}_{2}$, which then gets coordinated with the metal ion in situ. The additional peak observed at $1060 \mathrm{~cm}^{-1}$ was assigned to coordinated DMSO ${ }^{17}$; though the distinction between coordinated and uncoordinated DMSO cannot be made out due to the breadth of the peak.

When complex 2 is boiled with conc. $\mathrm{HCl}$ using the reported procedure ${ }^{7}$, the anticipated peak due to $v\left(\mathrm{~N}_{2}\right)$ disappears which further substantiates the presence of coordinated dinitrogen in 2 . Furthermore, in the lower region of the spectrum of this complex, a weak peak observed at $\sim 420 \mathrm{~cm}^{-1}$ is not observed in the spectrum of the free ligand. This is considered to arise from $v\left(\mathrm{Ru}-\mathrm{N}_{2}\right)$ vibration ${ }^{18}$ whereas the peak due to $v\left(\mathrm{PF}_{6}^{-}\right)$observed at $\sim 840 \mathrm{~cm}^{-1}$ is consistent with our earlier report ${ }^{11}$.

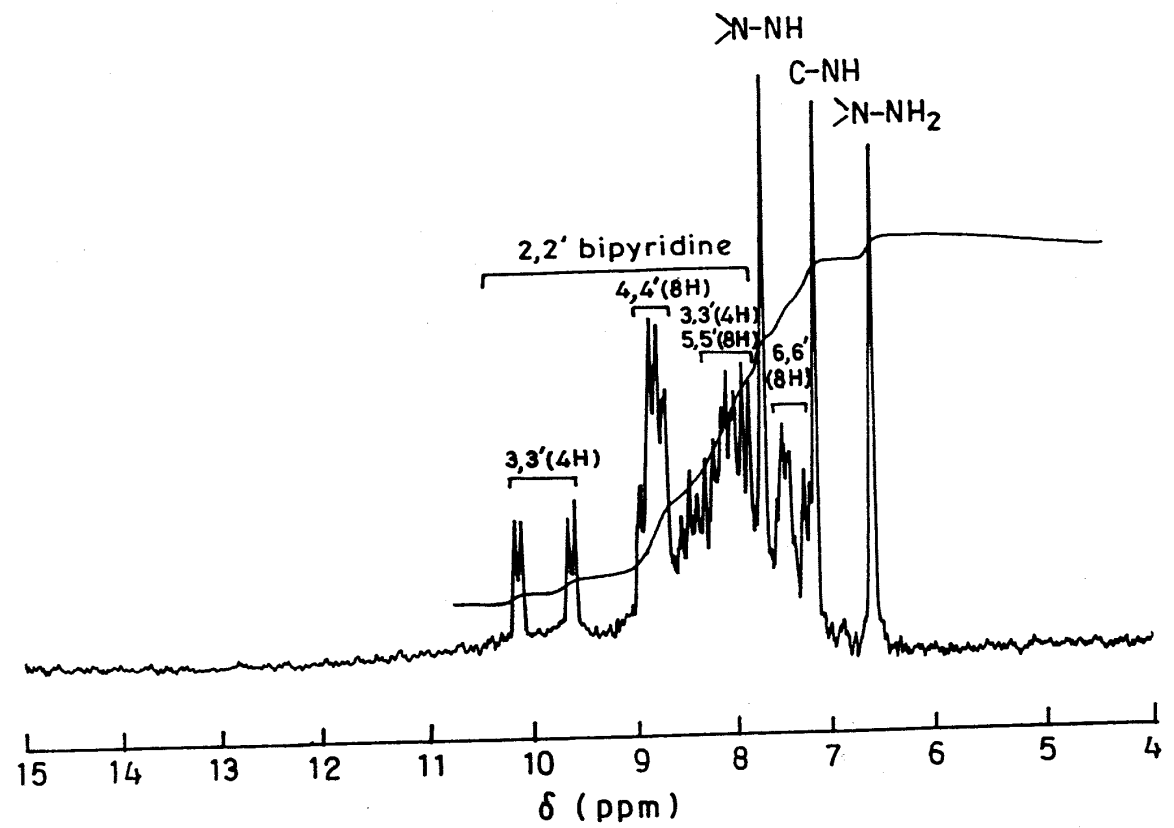

Figure 1. ${ }^{1} \mathrm{H}$ NMR spectrum of $\left[\mathrm{Ru}_{2} \mathrm{~L}(\mathrm{bpy})_{4}\left(\mathrm{PF}_{6}\right)_{2}\right.$ in the region $\delta$ (ppm) 4.0-15.0 in DMSO- $d_{6}$ at room temperature $\left(\sim 25^{\circ} \mathrm{C}\right)$. 


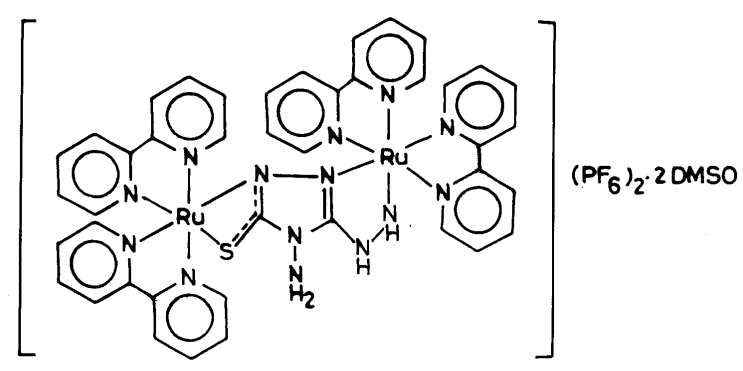

$\left[R u_{2} L(b p y)_{4}\right]\left(P F_{6}\right)_{2} \cdot 20 M S O(1)$

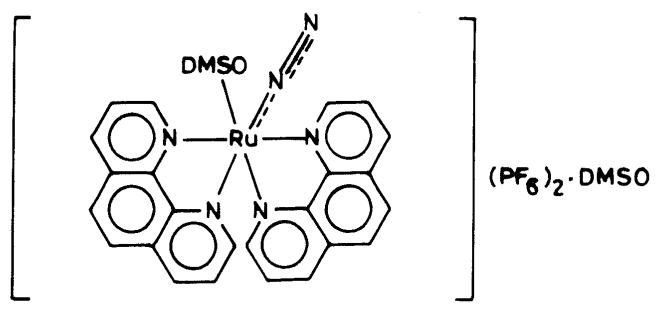

$\left[\operatorname{Ru}\left(\mathrm{N}_{2}\right)(\text { phen })_{2} \mathrm{OMSO}\right]\left(\mathrm{PF}_{6}\right)_{2}$ OMSO (2)

Figure 2. Proposed structures of Ru(II) complexes.

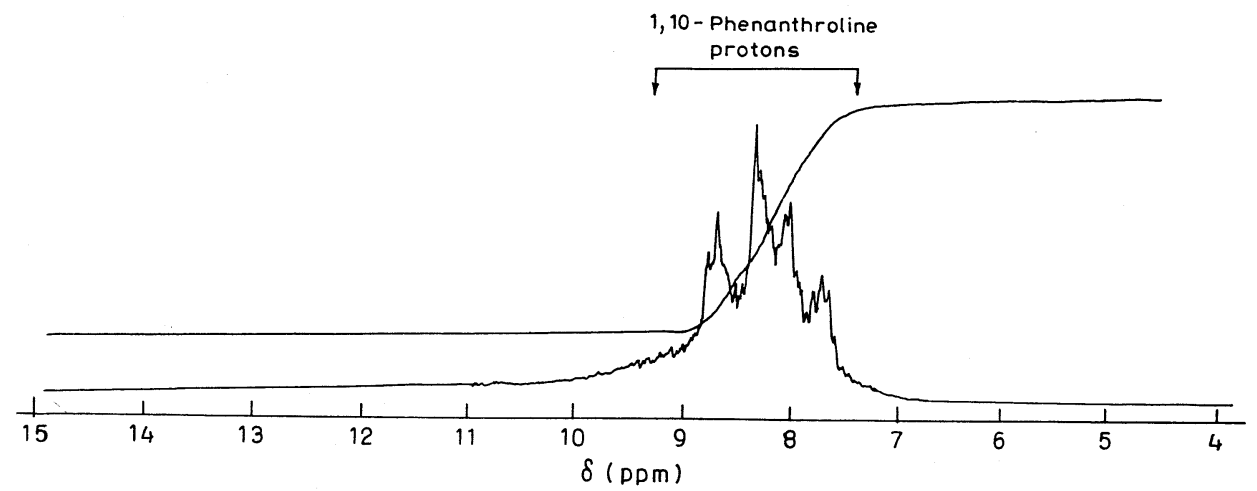

Figure 3. ${ }^{1} \mathrm{H}$ NMR spectrum of complex $\left[\mathrm{Ru}\left(\mathrm{N}_{2}\right)(\text { phen })_{2} \mathrm{DMSO}\right]\left(\mathrm{PF}_{6}\right)_{2}$ in the region $\delta(\mathrm{ppm}) 4 \cdot 0-15 \cdot 0$ in DMSO- $d_{6}$ at room temperature $\left(\sim 25^{\circ} \mathrm{C}\right)$.

\section{$3.2{ }^{1} H$ NMR and UV-Vis spectra}

The proton NMR spectrum of the free ligand $\mathrm{LH}_{2}$ recorded in DMSO- $d_{6}$ shows four singlets at $\delta 4 \cdot 0,5 \cdot 30,7 \cdot 10$ and $12.50 \mathrm{ppm}$ which were assigned ${ }^{13,14}$ to $-\mathrm{NH}_{2}, \mathrm{~N}-\mathrm{NH}_{2}$ (ring), $-\mathrm{NH}$ and $-\mathrm{NH}-\mathrm{C}=\mathrm{S}$ protons respectively. These peaks were exchanged with $\mathrm{D}_{2} \mathrm{O}$ but the free ligand peak at $\delta 12.50 \mathrm{ppm}$ disappears in the spectrum of complex 1 (figure 1) 


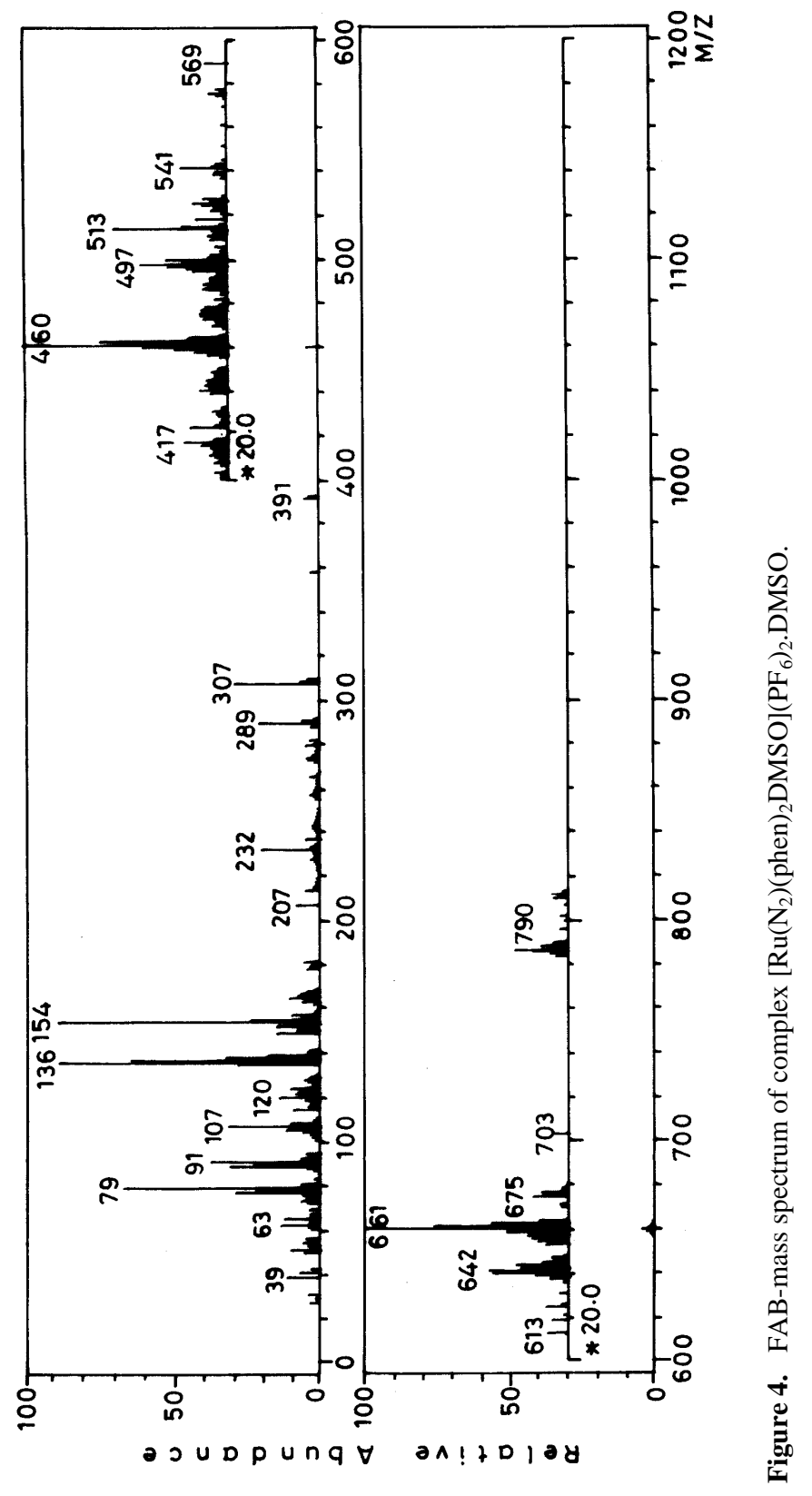




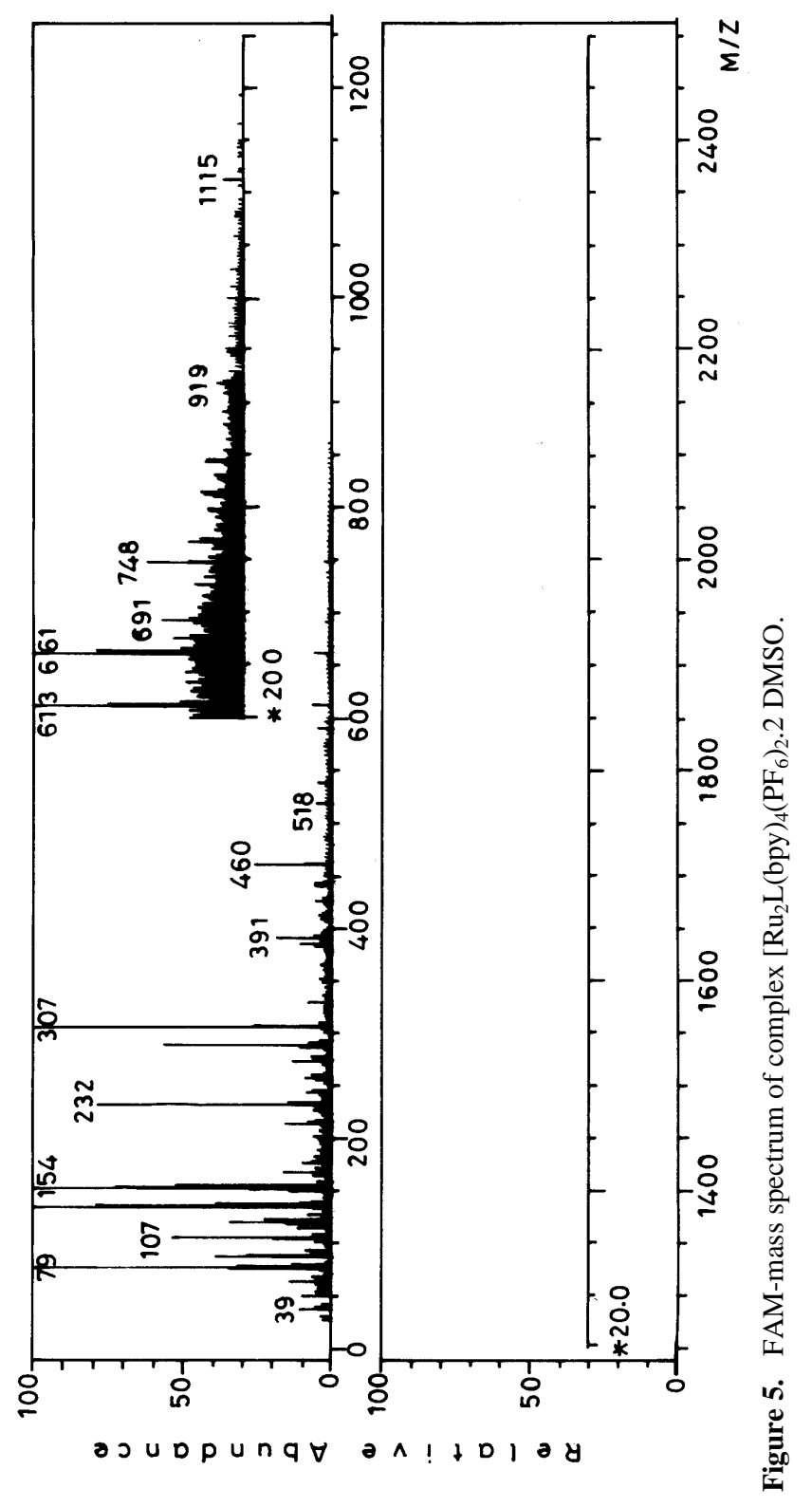


indicating that this proton is deprotonated during complexation with the metal ion. Peaks due to $\mathrm{N}-\mathrm{NH}_{2}, \mathrm{NH}-\mathrm{NH}_{2}$ and $-\mathrm{NH}$ protons observed at lower field, viz. $\delta 6 \cdot 60,7 \cdot 80$ and 7.20 (ppm) respectively, could be understood in view of their coordination with the metal ion. The larger downfield shift of $\mathrm{NH}_{2}$ protons and its integration area fitted with one proton suggests the structure of the ligand as shown in figure 2 and this further substantiated by the elemental composition showing $2 \mathrm{PF}_{6}^{-}$per two ruthenium (II) ions.

The presence of the $2,2^{\prime}$ bipyridyl group in complex 1 was considered in view of the peaks observed in its spectrum at $\delta 8 \cdot 00,8 \cdot 80,9 \cdot 60$ and $10 \cdot 2(\mathrm{ppm})$ due to $6,6^{\prime}, 5,5^{\prime}, 4,4^{\prime}$ and 3,3' protons respectively in consonance with reported ${ }^{19}$ values. It is further noticed that the ${ }^{1} \mathrm{H}$ NMR spectrum of the complex 2 (figure 3) does not show any peak due to ligand $\left(\mathrm{LH}_{2}\right)$ whereas multiplets due to phenanthroline protons are observed. This observation is further substantiated by its mass spectrum (figure 4) as compared to that obtained for complex 1 (figure 5). The additional peak observed at $\delta 2.65 \mathrm{ppm}$ was assigned to coordinated DMSO.

The UV/Vis spectral data of the complexes recorded in $\mathrm{MeCN}\left(10^{-5} \mathrm{M}\right)$ as shown in table 1 indicates that the broad peak observed between $460-424 \mathrm{~nm}$ can be assigned to MLCT ( $M \rightarrow$ polypyridyl) transition in view of an earlier report ${ }^{11}$, whereas transition arising from $\mathrm{LH}_{2}$ and polypyridyls cannot be distinguished owing to the overlapping regions.

Thus, in view of elemental $(\mathrm{C}, \mathrm{H}, \mathrm{N})$ analysis, NMR (figures 1 and 3), FAB mass (figures 4 and 5) and other spectroscopic data, the proposed structures for the ruthenium (II) complexes are depicted in figure 2 .

\subsection{Electrochemical and luminescence studies}

Cyclic voltammetric study for the ruthenium (II) complexes was carried out in $\mathrm{MeCN}$ $\left(5 \times 10^{-3} \mathrm{M}\right)$ solution containing $0 \cdot 1 \mathrm{M}\left[\mathrm{Bu}_{4} \mathrm{~N}\right]^{+} \mathrm{ClO}_{4}^{-}$as supporting electrolyte using $\mathrm{Ag} / \mathrm{Ag}^{+}$as reference and glassy carbon as working electrode. Complex 1 showed two quasi-reversible oxidations, centred at $+1.14 \mathrm{~V}$ and $+0.50 \mathrm{~V}$ (figure 6), most likely due to oxidation of two ruthenium (II) centres lying in two different environments as the free ligand did not show any oxidation in this region. Furthermore, complex 2, showed only one irreversible metal-based oxidation $\mathrm{Ru}^{\mathrm{III}} / \mathrm{Ru}^{\mathrm{II}}$ at $+1.18 \mathrm{~V}$ (figure 7 ). Reduction peaks observed at -1.77 and $-1.46 \mathrm{~V}$ in the complex 1 as well as at -1.75 and $-1.45 \mathrm{~V}$ in the complex 2 were assigned to reductions of bipyridyl and phenanthroline respectively in view of earlier reports ${ }^{11,20,21}$.

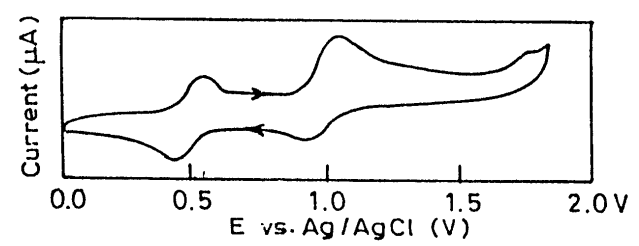

Figure 6. Cyclic voltammogram of $\left[\mathrm{Ru}_{2} \mathrm{~L}(\mathrm{bpy})_{4}\right]\left(\mathrm{PF}_{6}\right)_{2} .2 \mathrm{DMSO}$ in $\mathrm{MeCN}$ solution $\left(5 \cdot 0 \times 10^{-3} \mathrm{M}\right)$ using $0.1 \mathrm{M}$ TBAP as supporting electrolyte, $\mathrm{Ag} / \mathrm{Ag}^{+}$as reference electrode and glassy carbon as working electrode at scan rate $=400 \mathrm{~m} \mathrm{Vs}^{-1}$. 


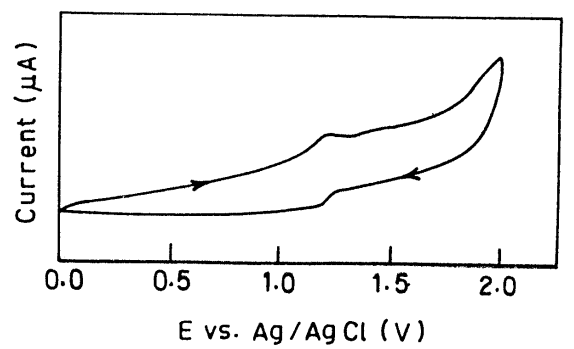

Figure 7. Cyclic voltammogram of $\left[\mathrm{Ru}_{2}\left(\mathrm{~N}_{2}\right)(\text { phen })_{4}\right]\left(\mathrm{PF}_{6}\right)_{2} \cdot 2 \mathrm{DMSO}$ in $\mathrm{MeCN}$ solution $\left(5 \cdot 0 \times 10^{-3} \mathrm{M}\right)$ using $0 \cdot 1 \mathrm{M}$ TBAP as supporting electrolyte, $\mathrm{Ag} / \mathrm{Ag}^{+}$as reference electrode and glassy carbon as working electrode at scan rate $=400 \mathrm{~m} \mathrm{Vs}^{-1}$.

Luminescence data shown in table 1 indicate that dinuclear ruthenium (II) 2,2'bipyridyl and mononuclear ruthenium (II) 1,10-phenanthroline complexes emit at 614 and $596 \mathrm{~nm}$ respectively when they are excited at $440 \mathrm{~nm}$. The observed intense luminscence from the mononuclear ruthenium (II) complex as compared to that from the dinuclear ruthenium (II) complex is consistent with the earlier report ${ }^{22}$.

\section{Conclusion}

Oxidation of hydrazino ligand $\left(\mathrm{LH}_{2}\right)$ in presence of $\mathrm{Ru}(\mathrm{Phen})_{2}$ unit can be understood in terms of planarity and rigidity of 1,10-phenanthroline ring as compared to that of the 2,2'bipyridine ring ${ }^{23}$. However, this surmise calls for further and more in-depth investigation.

\section{Acknowledgements}

We thank Prof Koji Araki (Tokyo University, Japan) for his help in spectral and electrochemical measurements and the anonymous referee for his/her valuable suggestions for improving the paper.

\section{References}

1. Patti S A, Bodiger B M, Kudasi S M and Kulkarni V H 1984 J. Indian Chem. Soc. 61713

2. Ram V J, Dube V, Pieters L A C and Vlietinck A J 1989 J. Heterocycl. Chem. 26625

3. Kane J M, Dudley M W, Sorenson S M and Miller F P 1988 J. Med. Chem. 311253

4. Sung K and Lee A 1992 J. Heterocycl. Chem. 291101

5. Sinha A K, Rastogi S N, Patnaik G K and Srimal R C 1993 Indian J. Chem. B32 738

6. Leclerc G, Amlaiky N and Rout B 1989 Eur. J. Med. Chem. 1769

7. Cotton F A and Wilkinson G 1988 Advanced inorganic chemistry (New York: John Wiley) p. 887

8. Douglas B, Daniel D M and Alexander J 1994 Concepts and models of inorganic chemistry (New York: John Wiley) p. 749

9. Deeth R J and Langford S A 1995 J. Chem. Soc., Dalton Trans. 1

10. Hartshorn R M and Barton J K 1992 J. Am. Chem. Soc. 1145919

11. Mishra L, Yadaw A K, Choi C S and Araki K 1999 Indian J. Chem. A38 339

12. Sullivan B P, Salmon D J and Meyer T J 1978 Inorg. Chem. 173334

13. Iqbal R, Rama N H, Ahmad N, Zamani K, Ebrahim S and Iqbal N 1998 Indian J. Chem. B37 506

14. Gupta R, Paul S, Gupta A K, Kachroo P L and Bani S 1998 Indian J. Chem. B37 498

15. Chatt J, Jonathan R D and Raymond L R 1978 Chem. Rev. 78589 
16. Nakamoto K 1978 Infrared and Raman spectra of inorganic and coordination compounds (New York: John Wiley) p. 301

17. Nakamoto K 1978 Infrared and Raman spectra of inorganic and coordination compounds (New York: John Wiley) p. 345

18. Allen A D, Bottomley F, Harrish R O, Reinsalu V P and Senaff C V 1967 J. Am. Chem. Soc. 895595

19. Mishra L, Choi C S and Araki K 1997 Chem. Lett. 447

20. Beer P D, Dent S W, Fletcher N C and Wear T J 1996 Polyhedron 152983

21. Lawrence G A 1985 Polyhedron 4817

22. Boyd S, Strouse G F, Jones W E and Meyer T J 1990 J. Am. Chem. Soc. 1127395

23. Sammes P G and Yahioglu G 1994 Chem. Soc. Rev. 23327 